\title{
Por uma Metodologia de Transformação na Encruzilhada Entre a Educação Somática e a Tecnologia: Tornando-se Outro...*
}

\author{
**Isabelle Choinière \\ ***Tradução: Cláudia Sachs
}

\begin{abstract}
Resumo
Este artigo apresenta uma visão geral das motivações por trás de minha abordagem artística e uma descrição da pesquisa atual. Meu processo artístico visa a transformação do corpo com base em referências táteis, cinestésicas e vivenciais. Tomamos o experiencial como matéria-prima. Este processo abre inevitavelmente códigos gestuais alternativos, modos performativos e comportamentos. Como resultado, é possível considerar uma nova relação entre Educação Somática e tecnologia capaz de gerar novos paradigmas estéticos, cognitivos e comunicacionais. Aqui, a tecnologia ativa um processo que reconfigura a atividade sensório-perceptiva e leva a uma mudança da corporalidade (corporalité) que por sua vez gera corporeidade (corporéité). Esta dinâmica é baseada no desenvolvimento de uma noção de potencialidade corpórea - ou intervalo - e introduz a noção de emergência através da qual uma possível organização de uma nova forma experimental nas artes cênicas pode aparecer. Christine Buci-Glucksmann fala do intervalo como o equivalente ao termo japonês Mâ (2003: 89), explicando-o como uma potencialidade latente presente no interior do virtual. Defendo que o virtual é parte do corpo físico e mostro como esses conceitos podem ser ligados como os fundamentos de uma metodologia que eu desenvolvi com bailarinos. Esta metodologia é de uma natureza evolutiva e é baseado em estratégias de desestabilização de três componentes da educação somática que eu já experimentei a fim de recriar o que Hubert Godard chama de "um real sempre flutuante “ (Godard apud Kuypers 2006: 60).
\end{abstract}

\section{Palavras-chave: metodologia - educação somáti-} ca - inter-subjetividade - corpo mediático - cognitividade - emergência

\begin{abstract}
This article presents an overview of the motivations behind my artistic approach and a description of current research. My artistic process aims at a transformation of the body based on tactile, kinesthetic and experiential references. It takes the experiential as its raw material. This process inevitably opens up alternative gestural codes, performative modes and behaviours. As a result, it is possible to consider a new relationship between somatics and technology capable of engendering new aesthetic, cognitive and communicational paradigms. Here, technology activates a process that reconfigures sensory-perceptual activity and leads to a change of corporality (corporalité) that in turn generates corporeality (corporéité). This dynamic is based on developing a notion of corporeal potentiality - or interval - and introduces the notion of emergence through which an eventual organization of a new experiential form in the performing arts can appear. Christine Buci-Glucksmann speaks of the interval as the equivalent of the Japanese term Mâ (2003: 89), explaining it as a latent potentiality present within the virtual. I argue that the virtual is part of the physical body and show how these concepts can be linked as the foundations of a methodology which I have developed with dancers. This methodology is one of an evolutive nature and is based on strategies of destabilisation of three components of somatics that I have experimented with in order to recreate what Hubert Godard calls 'an ever fluctuating real' (Godard
\end{abstract} in Kuypers 2006: 60).

keywords: methodology - somatic - inter-subjectivity - mediated body - cognition - emergence

\footnotetext{
* Publicado originalmente pela Intellect Ltd em CHOINIËRE, Isabelle. For a methodology of transformation at the crossroads of the somatic and technology: Becoming another... Journal of Dance \& Somatic Practices, vol. 5, n.1, 2013, p. 95-112. doi: 10,1386 / JDSP. 5.1.95_1.

** Doutora em Philosophy of Integrative Arts (Intercorporeidade e Tecnologia) da Planetary Collegium, Universidade de Plymouth. Artista, pesquisadora, autora e professora de novas práticas performativas contemporâneas. E-mail: isabellechoiniere@gmail.com

***Doutora em Teatro pela Universidade Estadual de Santa Catarina. Bolsista PNPD do Programa de Pós Graduação em Artes Cênicas da Universidade Federal do Rio Grande do Sul. Email: claudiasachs@terra.com.br**
} 


\section{Uma história resumida sobre a problemática das interfaces}

O discurso dominante da performance de palco contemporânea trata da interface, especificamente, as interfaces que integram tecnologias. Esse discurso é baseado em uma visão dualista e materialista do mundo ocidental, em uma 'cultura de objetos' como identificados por Christine Buci-Glucksmann¹ (2003). Na seção dedicada à metodologia, explico como é necessário desenvolver o pensamento ingrativo para evitar tais armadilhas redutivas, assim como para investir nas questões da corporalidade. Esta abordagem às interfaces, concebida em grande parte nas artes visuais, é a principal adotada nas artes cênicas atualmente.

Visões tradicionais sobre a interface, localizadas na intersecção da tecnologia e do humano, formalizam objetivos pragmáticos de comunicação destinados a traduzir e transformar a linguagem do corpo humano e da linguagem algorítmica que encontram-se no cerne da tecnologia informática (Quinz 2003a). Para Quinz ${ }^{2}$, que analisa a questão do ponto de vista das artes visuais e de mídia, mesmo se o conceito de interface venha a evoluir no futuro, permanece o fato de que, embora o conceito de interface possa ser refinado, ele ainda opera de acordo com princípios de seleção e redução que funcionam como contraponto ao corpo que ele compara a uma interface fisiológica extremamente complexa. (Quinz 2003a, 2003b)3.

$\mathrm{Eu}$, então, cheguei à seguinte reflexão: a fim de alcançar a complexidade relacional que eu desejava com a minha mais recente criação, eu não podia mais usar as interfaces que me estavam sendo propostas, mas necessitava avançar para princípios mais orgânicos, a fim de gerar a complexidade desejada. Com este objetivo, eu fiquei interessada em repensar a relação entre educação somática e tecnologia.

\section{Uma descrição resumida da última fase da criação atual}

Seguindo essas hipóteses, minha experimentação mais recente tomou a forma de uma criação híbrida que explora as relações entre o corpo físico em movimento e a tecnologia, ou, mais especificamente, entre princípios da Educação Somática e a tecnologia.

O trabalho se assemelha a uma escultura tridimensional em movimento. São cinco bailarinos parcialmente nus em cena que estão quase sempre em contato uns com os outros. Este "corpo coletivo" foi concebido através de uma exploração pessoal que toma como referência sensações táteis e cinestésicas, bem como uma dinâmica criativa enraizada no experiencial, no evolutivo e no que é transversal. Este corpo se move, e foi desenvolvido por meio de estratégias que se assemelham com "corpo fluido" de Trisha Brown, enquanto que, ao mesmo tempo, radicalizam o "corpo tátil" de Steve Paxton (Fontaine, 2004). Um ambiente sonoro gerado em tempo real é produzido pelas diferentes dinâmicas de movimento da coreografia. Esta paisagem sonora também tem a particularidade de ter sido criada a partir de uma dinâmica colectiva, um "corpo sonoro coletivo", que se torna um sexto bailarino com sua dinâmica particular, sua temporalidade e sua relação com o espaço.

Os dispositivos tecnológicos implantados se destinam a permanecer invisível. O primeiro dispositivo é um sistema de microfone sem fio usado pelos bailarinos sob turbantes negros. É escondido. O segundo dispositivo é um programa de computador que é concebido para espacializar o som. Graças a esses dispositivos tecnológicos, os artistas são capazes de gerar som mediatizado em tempo real. Expressões gestuais e auditivas são captadas pelos microfones sem fio e transformadas em sinais de áudio que são transmitidos ao vivo (processados e espacializados) dentro do ambiente da performance. Além disso, os sons e gestos produzidos por cada performer retornam como ecos de uma manifestação mediatizada do corpo e também estendem-se para os outros artistas, ampliando, assim, os cinco corpos como um único corpo sonoro coletivo. Numa fase anterior do projeto, fontes sonoras foram tratadas coletivamente. Na fase atual, as fontes são isoladas e espacializadas em diferentes arranjos espaço-temporais que complexificam o fenômeno perceptivo e a organização performativa/ mediatizada dos elementos.

A cenografia do trabalho consiste em três espaços circulares, sendo o primeiro o espaço da performance no qual os bailarinos se movimentam. Possui cerca de seis metros de largura e está posicionado no centro. $\mathrm{O}$

\footnotetext{
$1 \quad$ Christine Buci-Glucksmann é uma filósofa francesa e Professora Emérita da Universidade Paris 8. Seu trabalho centra-se na estética do barroco, Japão e arte digital.

Quinz, é um teórico que atualmente ensina Estética, Artes e Tecnologias na Universidade Paris VIII.

Para uma análise mais desenvolvida sobre interfaces e paradigmas, veja:

Choinière, I. (no prelo), "The interval as a new approach to interfaces: Towards a cognitive and aesthetic paradigm of communication in the performing arts" (O intervalo como uma nova abordagem para interfaces: Rumo a um paradigma cognitivo e estético de comunicação nas artes cênicas ), capítulo IV.
} 
público é posicionado em torno deste círculo bem próximo ao espaço dos bailarinos. O terceiro círculo exterior é formado por oito alto-falantes que fazem parte do sistema de som espacializado e engloba todo o espaço da performance. Localizado entre os alto-falantes e a arena/espaço dos bailarinos, o público participa plenamente da desestabilização sensorial e perceptiva que estou experimentando. Com essa proximidade, estou conscientemente tentando provocar um efeito hipnótico que resulte do ser confrontado com esta forma complexa de carne e de som: uma massa de carne que canta, fala, geme.

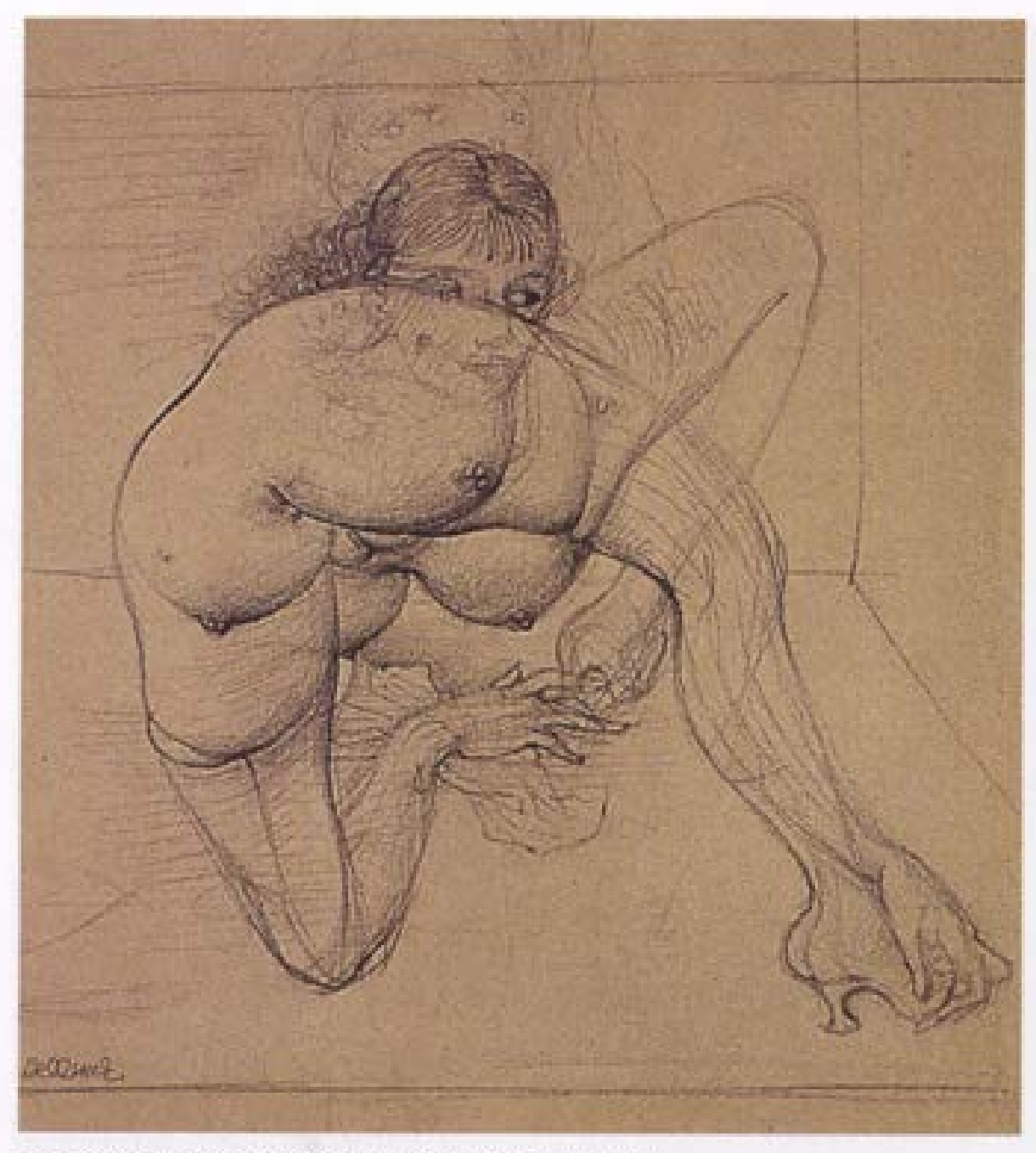

140. Cephalopode, années quarante, dessin au crayon.

Figura 1: 140. Céphalopode, ano quarenta, desenho em crayon. Dourthe (1999), p.102.

A proximidade dos corpos nus dos bailarinos retira os espectadores de suas referências e distância analíticas habituais. A massa de carne em movimento provoca uma primeira perda de suporte, uma de-hierarquização, já que o público se encontra dentro da carne ${ }^{4}$. De-hierarquização é uma estratégia que emprego onde partes do corpo não desempenham seus papeis convencionais. Por exemplo, pernas desempenham o papel de braços ou são duplicadas, como na obra de Hans Bellmer, um pintor alemão que foi uma fonte de inspiração para o trabalho. Ao mesmo tempo, os espectadores ouvem esta massa de carne. Uma segunda perda de suporte ocorre, assim, ao serem imersos numa forma viva de som. Eles encontram-se na forma, no hiper íntimo, e no som que se move ao seu redor e penetra seus espaços. Estas duas formas - a carne dos cinco bailarinos emaranhada com o som - borram códigos e suportes.

$4 \quad$ Estas experiências foram documentadas. Reuniöes seguiram cada apresentaçấo e espectadores, pesquisadores ou críticos de arte presentes foram entrevistados e alguns, filmados. Ver bibliografia de artigos que documentam os resultados destas fases do work in progress que foram publicados em revistas especializadas e sites de pesquisa. Os resultados destas fases do trabalho também serão publicados em minha tese de doutorado. 
O trabalho propõe-se a ser uma encenação da presença e da carne dessa massa humana em sua dimensão material e interconectada. O desejo de trabalhar com um corpo coletivo reflete uma necessidade de encontrar uma forma performativa que possa espelhar a interconectividade e a complexidade do nosso mundo. Essa orientação se assemelha as obras dos pós-modernistas que, em sua própria época e contexto, redefiniram as estruturas e códigos da performance e da dança. Trabalhos como Roof Piece (1973) ou Walking down the Side of a Building (1970) de Trisha Brown, Victory 14 (1966) de Deborah Hay, Temple (1974) e Scenario (1971) de Alwin Nikolais, ou as improvisações de Steve Paxton, para citar apenas alguns, refletem essas importantes mudanças. Para melhor ilustrar minha ideia, é interessante analisar como Trisha Brown construiu seu "corpo fluido":

A lógica temporal de movimento é perturbada: o início de um movimento em uma parte do corpo as sume um outro movimento que ainda não está concluído [‥]. Este jogo no inacabado' no revezamento e no desvio provoca um efeito de surpresa e revigora constantemente o movimento [‥]· A coreógrafa cria um movimento que ela qualifica como multidirecional [‥] (Fontaine, 2004).

Para Geisha Fontaine (2004), “ isso introduz uma configuração diferente”. Para Guy Scarpetta, (1992 citado em Fontaine 2004), o movimento browniano é quase uma revolução: é um “corpo em transição” incorrigível.

\section{Uma mudança de perspectiva na prática}

Meu interesse em trabalhar com interfaces em tempo real surgiu ao desenvolver este tipo de fisicalidade alterada, especificamente, que poderia levar a uma modificação da corporeidade. A necessidade de desenvolver um relacionamento com uma interface que pudesse aumentar a corporeidade e não empobrecê-la, fazia parte dessa experimentação. E eu senti a necessidade de fazer uma ruptura com o tipo de instrumentalização aos quais os artistas são muitas vezes submetidos com a tecnologia.

A complexidade dos cinco corpos em constante contato uns com os outros - um corpo coletivo - exigiu que eu evitasse uma relação causal com a tecnologia. Eu estava à procura de uma interface que pudesse agir sobre a organização sensório-perceptivo dos indivíduos: para ambos artista e espectador. A relação com a tecnologia redefine modos de percepção. A abordagem fenomenológica que experimentei, através de estratégias de desestabilização que acabo de mencionar, influenciou minha maneira de pensar - e sentir - o corpo e, assim, de organizar o trabalho.

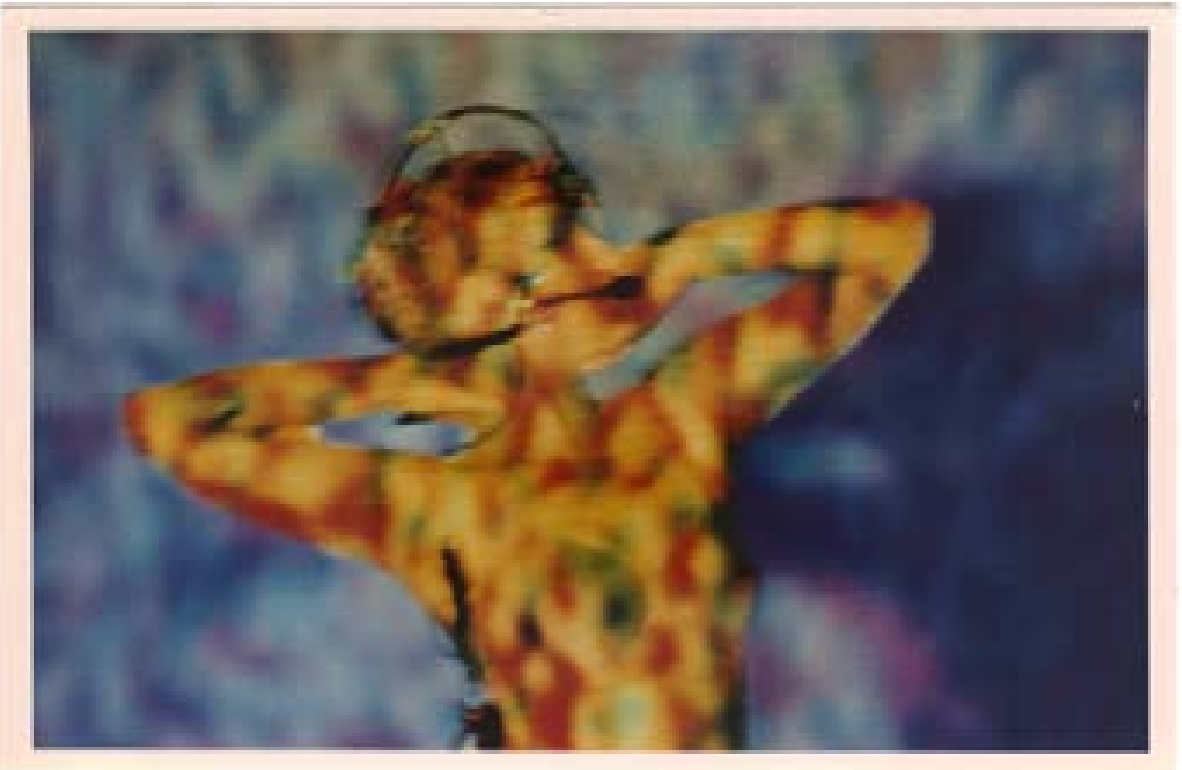

Figura 2: Communion (Le partage des peaux II) (1995-2000), concebido e executado por Isabelle Choinière. Photógrafo : Marc Deserrano 
A ideia de tecnologia experienciada e expressada artisticamente como um ambiente, corresponde à noção de um corpo dilatado que também orientou meu processo. Ele foi iniciado com trabalhos sobre molecularização ${ }^{56}$ na minha primeira criação Communion $^{7}$ (1995). Foi realizada com o desenvolvimento de som sendo gerado em tempo real, criando a sensação de um corpo sonoro vibrátil que nos rodeava (eu e meus bailarinos). Esta experimentação foi prosseguida na minha segunda criação, La Demence des Anges ${ }^{8}$ (1999), onde eu experimentei o corpo como um corpo dilatado e não como um duplo.

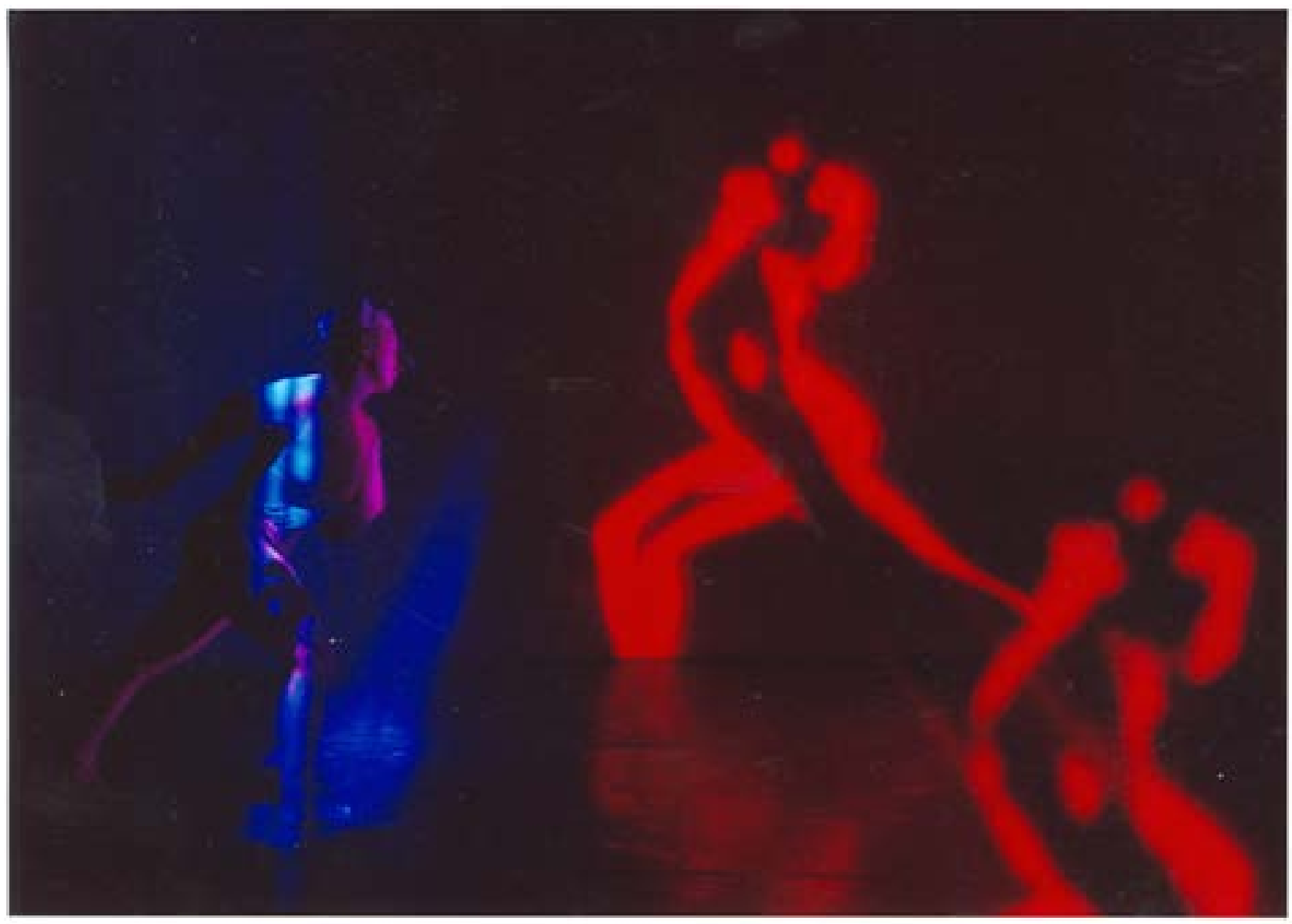

Figura 3: La Démence des anges (Le partage des peaux II) (1999-2005), concebida por Isabelle Choinière e executada por Isabelle Choinière e Alyson Wishnovsky. Fotógrafo : Frédérique Bolté.

No meu mais recente work in progress, a experimentação com um corpo sonoro em tempo real provocou ainda uma outra modificação: a de "conceito de ficção" avançado de Bernard (2001) como a sensação de um corpo em um estado de difração. O "conceito de ficção" de Bernard vem sendo descrito como a projeção de uma corporalidade que é exteriorizada (Bernard 2001; Kuypers 2006; Corin 2001). O performer imagina e projeta sua anatomia no espaço antes de agir no mundo físico. É uma corporalidade imaginada. No que diz respeito à minha idéia de corpo em estado de difração, eu diria que o corpo físico se torna mais complexo, e o corpo mediado emanado a partir daí provoca uma mudança no estado de presença, mesmo uma mudança na essência desta presença9 ${ }^{9}$, logo, uma evolução do "conceito de ficção"de Bernard.

\footnotetext{
5 Através de um processo que desenvolvi que pode estar relacionado com o "conceito de ficção"de Michel Bernard (2001). 6 A forma de presença que eu chamo molecularização refere-se a uma forma de presença que eu desenvolvi no meu primeiro trabalho Communion. Envolve uma sensação de corpo num estado de expansão. O performer imagina e sente as moléculas de seu corpo como sendo espalhadas no espaço e formando um corpo que eu chamo estendido ou dilatado e que também corresponde a teorias taoístas. A imagem visual que eu usaria para descrever esta sensação é de um ambiente imersível feito de pixeis eletrônicos de vídeo. Quando menciono os escritos de Deleuze e Guattari، refiro-me a sua noção de um corpo hierárquico (Deleuze \& Guattari, 1980). Eu não estou me referindo a sua noção de molecularização que é diferente do fenômeno da molecularização que eu desenvolvi enraizado em uma forma de cognição baseada em práticas somáticas que eu defendo neste texto.

$7 \quad$ Primeira versão criada em 1995 e modificada pela última vez em 2000.

$8 \quad$ Primeira versão criada em 1999 e modificada pela última vez em 2005.

9 O corpo é visto no palco e ocupa um espaço específico no espaço físico. Enquanto isso, a memória e a imaginação são
} 

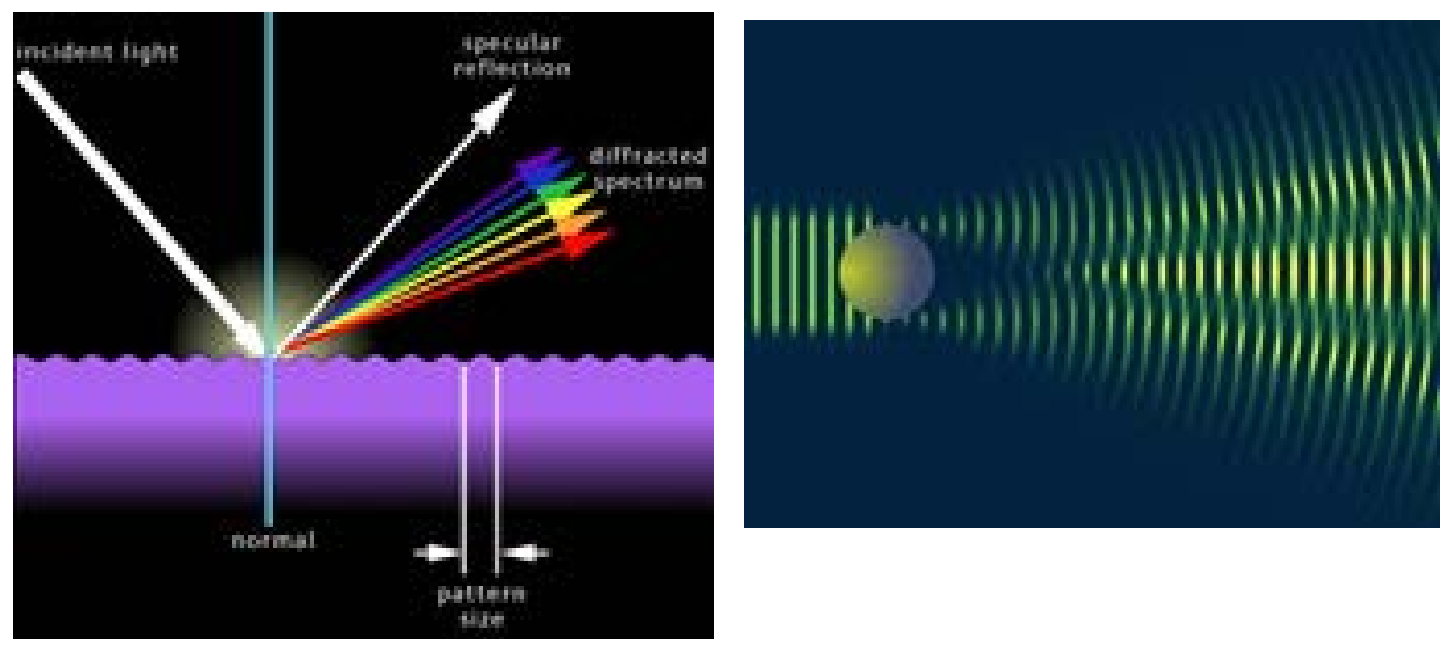

Figura 4: Difração.

http://www.aucoeurdelaplanete.com/Termes-Ästronomie/Diffraction.html.

http://www.google.ca/search?q=image+diffraction\&hl=fr\&client=firefox-a\&hs =NKU\&rls=org.mozilla:fr:official\&prmd=imvns\&tb$\mathrm{m}=\mathrm{isch} \& \mathrm{tbo}=\mathrm{u} \&$ source $=$ univ\&sa $=\mathrm{X} \& \mathrm{ei}=$ WCIfT-XOBNCH0QG5w6EG\&ved $=0$ CDoQsAQ\&biw $=1011 \& \mathrm{bih}=836$ Acessado em 24 de janeiro de 2012.

Uma complexidade experiencial é revelada que reflete o que Lygia Clark descreveu como “... o corpo [que] é ambos singular e plural”10 (Luz 1975; Rolnik \& Diserens 2005). Este processo não implica uma perda de self, mas de fato uma 'complexificação do self' juntamente com a noção de presença performativa. Um novo comportamento performativo é criado com a interface em tempo real e uma consideração do corpo mediado como uma entidade 'pertencente' ao corpo físico e decorrente da sua evolução e complexidade. Não é uma forma separada, superimposta ou hierárquica do corpo físico como sugerido por Deleuze e Guattari (1980) ou Pitozzi (2008a, 2009a, 2009b, 2010).

Os resultados desta pesquisa causaram também um impacto significativo sobre a estética do projeto como uma proposição de um modelo baseado nas palavras gregas aisthetikos como '... a capacidade de perceber ou compreender' e aisthesis como ‘sensação' (Darriulat 2006; Buci -Glucksmann 2003). Basear um trabalho performativo em sensação e percepção me leva a conclusões semelhantes em um nível filosófico e artístico ${ }^{11}$ como Buci-Glucksmann (2001, 2003): para a concepção e testagem de um novo paradigma estético.

Outra radicalização do corpo performativo é proposta por Suely Rolnik ${ }^{12}$, psicanalista brasileira, crítica cultural e colaboradora de Deleuze e Guattari. Analisando a relação entre o artista e espectador nas artes cênicas, e referindo-se a ambos os corpos dos performers e dos espectadores pela perspectiva da psicanálise e da crítica cultural, Rolnik sugere que não é mais uma questão de pele, mas sim uma 'dissolução' de superfície - que ela chama de "limite psico-corporal" - que cria um novo paradigma de comunicação: intersubjetividade. Esse estado torna-se possível por meio do desenvolvimento de ligações psico-corporais que são 'vibratórias' $(2006)^{13}$. O espaço entre os intérpretes, bem como o espaço entre os intérpretes e o público, não está vazio, mas sim preenchido com um estado de vibração de comunicação. Tanto para o performer como para o espectador, é necessário aceitar ficar num estado frágil ou correr certos riscos, como uma forma de "reconhecimento" entre os corpos e dissolução da "barreira psico-corporal”(Rolnik 2006, 2007b, 2007c).

No contexto da arte interativa, Ascott sustenta a ideia de que "o ato de mudança torna-se uma parte vital da experiência estética total do participante"([1966-1967] 2003: 150). Esta proposição tem relevância direta elementos que são projetados para o exterior. Eles constituem uma corporalidade imaginada. A projeção ocorre, portanto, a partir de um "aqui" (de l'ici) (Pitozzi 2008a).

10 Em "Le corps est la maison: Sexualité, envahissement du 'territoire' individuel", Lygia Clark descreve a fase sensorial de sua abordagem chamada "Nostalgia do Corpo" nestes termos:

[n] oh, o corpo é uma casa. E uma experiência de comunidade. Não há regressão porque há uma abertura dos seres humanos em relação ao mundo. O corpo está ligado a outros em um corpo comum. Ele incorpora a criatividade dos outros na invenção coletiva da proposição [...]. Mas cada experiência era individual e arriscava fechar em si mesma, ao passo que agora, é tanto pessoal quanto coletiva, uma vez que está constantemente ligada a de outros em meio à mesma estrutura polinuclear. (Luz 1975; Rolnik \& Diserens 2005).

11 Buci-Glucksmann fazem sua análise artística aqui em relação a arquitetura.

12 Rolnik é crítica cultural, psicanalista e professora da Universidade de São Paulo, Brasil, onde dirige um programa de doutorado sobre a subjetividade contemporânea.

13 Conferência realizada em São Paulo, Brasil, em 2006. 
para o contexto do corpo performativo e, como resultado, para a criação de novos modelos estéticos que reflitam a dinâmica de integração no mundo dos vivos. Os procedimentos metodológicos que proponho mais adiante neste artigo foram desenvolvidos com uma lógica integrativa. Este novo paradigma estético torna-se possível por meio da desestabilização do corpo, investindo numa atividade multissensorial de risco e enriquecendo o processo criativo com um novo paradigma de comunicação. Minha pesquisa mais recente revela que cada vez mais artistas estão interessados na mudança de perspectiva que surge quando levamos em conta a interioridade em vez da exterioridade, ou daquilo que é espetacular. Esta perspectiva implica o corpo e o experiencial. Ela está mais preocupada com as mudanças produzidas dentro do corpo em vez de eventos externos causados em/ por um ambiente, tão típico da maioria das produções artísticas que envolvem tecnologia. Aqui estou pensando na instalação interativa de Diana Gromala "O Livro de Carne" (2007), que envolveu uma profunda investigação sobre "as maneiras como certas formas de arte interativa podem e provocam respostas viscerais" $(2007: 03)^{14}$ , ou o trabalho de Myriam Gourfink em micro movimento ${ }^{15} \cdot{ }^{16}$ Essas abordagens me levaram a reexaminar a relação entre educação somática e tecnologia e como ela poderia criar novos paradigmas quando as tecnologias ativam um processo capaz de reconfigurar a atividade sensório-perceptivo e assim modificar corporalidade para gerar corporeidade. Essa dinâmica levou-me para a noção de emergência e da possibilidade de organização de uma nova forma experimental nas artes cênicas.

Se a relação com a tecnologia redefine os nossos modos de percepção, proponho uma mudança na noção de interface em que a tecnologia não é mais considerada como um dos dois pólos da comunicação em causa, mas sim, uma ferramenta para o desenvolvimento de inter-subjetividade e uma modificação da corporeidade. Essa hipótese também vem na sequência de uma outra relação entre corpo e tecnologia: os conceitos de um corpo dilatado (corps élargi) e de tempo dilatado. Com a construção da intersubjetividade, defendo que um novo paradigma de comunicação torna-se possível através da ativação de uma potencialidade corpórea (Pitozzi 2008a, 2010), que é inerente ao corpo (Choinière 2014).

\section{Por uma metodologia de transformação}

Os princípios e os passos da metodologia que desenvolvi para o trabalho que está em andamento, refletem três paradigmas: um novo paradigma estético baseado em fluxo e no transicional (Glucksmann, 2001) ${ }^{17}$; um paradigma de comunicação com base na intersubjetividade de natureza antropofágica; por último, um paradigma cognitivo que resulta de uma apreciação e reintegração da inteligência específica do corpo. O conceito de "canibalismo cultural" foi cunhado pela primeira vez por Oswaldo de Andrade no Manifesto Antropofágico (1928). Este conceito refere-se à forma como, no contexto histórico do desenvolvimento cultural do Brasil, ocorreu um processo de canibalização de outras culturas. Este canibalismo cultural corresponde a um mecanismo de auto-afirmação cultural no que diz respeito à dominação cultural do pós-colonialismo europeu.

É uma forma de apropriação cultural. A referência específica ao conceito de canibalismo vem da Subjetividade Antropofágica de Suely Rolnik (Rolnik 2007a) na qual a autora usa o termo como o potencial de contaminação ontológica, integração e transformação.

A metodologia que estou propondo é, assim, de uma natureza transversal, evolutiva e sincrética. Baseia-se em novas relações que proponho entre a educação somática e a tecnologia. Esta estratégia também tem a especificidade de ser uma ferramenta para a elaboração de uma metodologia de pesquisa dinâmica e coletiva que implica análises evolutivas e adaptativas com base numa relação interativa entre teoria e prática. Essa metodologia é, portanto, uma metodologia reflexiva em que a prática e a teoria influenciam uma à outra de forma dinâmica.

\footnotetext{
14 Veja Diana Gromala, "Towards a Phenomenological Theory of the Visceral in the Interactive Arts", p.3, onde ela observa que, "visceral refere-se a sistemas cardiovasculares, respiratórios, uro-genitais e excretores que afetam a mente e o corpo em um continuum de consciência (...) obras de arte interativas, predominantemente concentram-se no exteroceptivo (estímulos de fora) e não nos sentidos interoceptivos (estímulos que surgem dentro do corpo, especialmente das vísceras)".

15 http://www.myriam-gourfink.com

16 De acordo com Pitozzi (2008a), Gourfink trabalha em uma dimensão sutil de presença que envolve um processo de visualização interior. Esse processo ativa um deslocamento, levando-a a perceber cada parte do corpo: a linha interna de tensão em movimento é privada de interrupção rítmica. Ela não envolve variações, apenas modulações.

17 O interesse da proposiçấo de Buci-Glucksmann reside no fato de que ela a relaciona com o conceito japonês de Mâ e o intervalo como constituintes de um espaço instável em que as fronteiras são destruídas: "[...] o virtual é a atualização de uma força e, portanto, as mentiras virtuais encontram-se no poder da forma é necessária para pôr fim a uma espécie de cegueira em relaçâo ao que é transitório, microscópico, a passagem das artes" (Buci-Glucksmann 2003).
} 


\section{A abordagem com performers}

A metodologia que empregamos com artistas consiste em cinco fases. Trata-se de estratégias de desestabilização em relação a três componentes da educação somática que eu tenho explorado a fim de reconstruir e recriar o que Hubert Godard chama de "um real sempre flutuante " (Godard apud Kuypers 2006: 60). É interessante notar que, recentemente, o trabalho de pesquisadores e bailarinos no campo da educação somática (Fortin 2009: 101) é hoje considerado como uma fonte válida de conhecimento, quando combinada com outras abordagens teóricas. Um exemplo é a metodologia de Godard que adota a educação somática como um guia para a sua pesquisa em medicina. Numa entrevista com Kuypers (2009: 58) Godard afirma que "anatomia é tomada como algo absoluto, enquanto que existe uma experiência fenomenológica de movimento que existe quando você chega em certo nível de propriocepção que pode ser considerada antes dos dados científicos." Ele continua, mencionando, por exemplo, que, hoje, "novas técnicas de imagens médicas confirmaram todas essas intuições ou formas de conhecimento empírico".

Voltando à apresentação de minha metodologia com performers, os cinco estágios envolvidos incluem:

1.Tornar-se consciente do corpo como um ambiente: o corpo movendo-se no espaço. Em seguida, obter os próprios suportes fenomenológicos, cinestésicos, perceptivos e experienciais dentro deste contexto.

2.Adicionar um elemento de desestabilização, por exemplo, uma abstração do espaço produzido quando a iluminação não permite que os bailarinos vejam as paredes, resultando numa perda de referências espaciais. Adicionar elementos tecnológicos como camadas extras de informações pode também adicionar outra camada de complexidade a ser integrada.

3.Instalar consciência da perda de suportes e a diferença que esta complexidade acarreta.

4.Dar tempo para integrar essa complexidade até o performer senti-la fisicamente em níveis perceptivos e cinestésicos: por exemplo, quando elementos de som ou vídeo imersivos são registrados fisicamente em nível vibratório. Trata-se de dar tempo para a reorganização sensorial e perceptiva em ensaios e através de um longo período de contato com os elementos das mudanças em questão (tecnológica, cenográfica, etc.), bem como através da consciência fenomenológica e experiencial.

5.A aquisição e integração de novas capacidades. Observação das mudanças que ocorrem no comportamento performativo e consciência de um novo elemento performativo e sua integração no processo criativo.

A prática normal de certos coreógrafos é de adicionar elementos tecnológicos ao processo coreográfico e pedir aos bailarinos para aprenderem a usar e operar estes dispositivos para gerar imagens, sons, etc. ditadas pelos objetivos do projeto. Até agora, não tenho conhecimento de processos criativos que concedam tempo para tomar consciência deles, e para a implementação e reorganização sensorial e perceptiva. Na abordagem normal, nenhuma mudança ontológica acontece; o corpo performativo é visto como um objecto, como um suporte, para a produção de tecnologia. O bailarino torna-se dividido, perdendo parte de suas qualidades performativas como bailarino, como resultado de ter que ouvir ou olhar para o que ele/ela está produzindo em vez de usar as tecnologias como um meio de auto-transformação e uma forma alternativa de atuação.

Não é preciso dizer que o método que eu emprego pressupõe que os artistas tiveram treinamento prévio em práticas somáticas ou em técnicas de dança específicas usadas em algum determinado projeto, por exemplo, contato-improvisação, bem como experiência em alguma prática de introspecção como a meditação. Eles também precisam estar confortáveis com a nudez e a proximidade com outros corpos e, por último, o desejo de investir em pesquisa que envolve risco, que é transdisciplinar e tecnológica. Todos esses fatores levam inevitavelmente a novos códigos gestuais e modos performativos.

O que quero dizer, e que está no cerne da minha discussão, é que este tipo de mudança cinestésica, apropriação e integração, são essenciais para artes cênicas que integram novas tecnologias. Engendrando reorganização sensorial e perceptiva, elas participam na elaboração de uma forma particular de cognição que eu defendo. Essas mudanças, semelhantes ao tipo de instabilidade que nos proporciona informações novas e 
adicionais, pertencem à esfera dos vivos e também ecoam as teorias de Burns (2009) e Laflamme (2009) sobre a necessidade de que as metodologias das pesquisas práticas e criativas sejam fundamentadas, a fim de serem bem sucedidas ${ }^{18}$. À luz dessas observações é, portanto, indispensável revisitar modos de exploração e produção e permitir o tempo necessário para integrar o surgimento de novos comportamentos performativos. Para ilustrar este ponto, alguns exemplos abaixo demonstram as estratégias de desestabilização que tenho desenvolvido.

\section{Definição e princípio do "corpo sonoro"}

O princípio do “corpo sonoro” é em si uma estratégia de desestabilização. Quando falo de um 'corpo sonoro', me refiro primeiramente a uma dimensão do corpo físico que é gerado em tempo real por bailarinos de uma forma que se alinha com a noção de um corpo dilatado. ${ }^{19}$ Para compreender este conceito, os bailarinos tiveram que desenvolver um sentido mais amplo de si: em seus movimentos e nas suas produções de som em tempo real, bem como na relação das duas entidades se entrelaçando intimamente a fim de tomar forma.

O corpo sonoro a que me refiro é uma emanação, uma dilatação do corpo físico que constitui uma vibração através da qual os bailarinos podem encontrar uma referência sensorial para a criação de um ambiente sonoro em tempo real. Insisto no fato de que este corpo sonoro não é um duplo, mas uma nova manifestação do corpo físico, e decorrente de um processo de aprendizagem cinestésico, que emerge da influência da tecnologia como um elemento de desestabilização exterioceptivo. Essa transformação do corpo requer tempo para adquirir e assimilar. É o produto de uma integração real da mudança que pode também levar a uma transformação de si mesmo, do self.

O que me interessa é que, quando se trabalha com um corpo sonoro coletivo, eu também posso intervir e renovar a sensorialidade e a percepção dos bailarinos. Por um lado, isso me forçou a abandonar modos de composição que já haviam sido experimentados. Por outro, ele me permitiu ir mais fundo numa construção do movimento que está em um estado de constante transformação. A partir desta perspectiva a sensorialidade reorganiza-se e a interioridade é mediada, uma vez que essa mesma interioridade está constantemente mudando e evolui no que diz respeito à desestabilização criada por uma ação tecnológica externa. Esta modificação da interioridade através da mediação permite uma renovação da percepção do movimento e do corpo que se move pelo espaço. É um dos elementos que permite evitar a esclerose que caracteriza muitas coreografias (Bernard, 2001) e, na minha opinião, constitui um dos aspectos mais importantes da pesquisa com tecnologia: a renovação da organização perceptiva, a fim de criar novas partituras de movimentos.

Mas isso não é tudo. Esta mesma dinâmica pode levar a uma evolução, e, portanto, à criação de outros tipos de comportamento performativo e, mais ainda, a modificações em projeções em performances que eu tenho pessoalmente experimentado e às quais me refiro neste artigo (difração, molecularização). Eu acredito que as tecnologias devem renovar a experiência da corporalidade. Trabalhar com a dimensão de um corpo sonoro significa agir sobre um processo de renovação sensorial, tanto no desenvolvimento do movimento quanto na projeção performativa. Renovação sensorial só pode ser conseguida através da prática constante ao longo de um período de tempo. Enrico Pitozzi descreve o efeito transformador desse processo como uma transição da representação para a transformação. Ele observa que o processo envolvido no trabalho com o "corpo sonoro coletivo",

impilicou na duplicação da dimensão enfática ou um processo de aprendizagem a'a distância' uma outra corporeidade envolvendo ambos artistas e público. Em outras palavras' pode'se dizer que uma relação enfática é estabelecida ${ }^{(-.)}$O espectador assiste à performance e seus estados perceptivos apelam diretamente a sua corporeidade' entrelaçando'se numa exacerbada e contaminada intersubjetividade. $O$ espectador está diretamente imerso no movimento que está assistindo pela via do "corpo sonoro" espacializado Este fenômeno transformador atua diretamente sobre uma redefinição de sua

\footnotetext{
18 O interesse da proposição de Buci-Glucksmann reside no fato de que ela a relaciona com o conceito japonês de Mâ e o intervalo como constituintes de um espaço instável em que as fronteiras sã̃o destruídas: "[...] o virtual é a atualização de uma força e, portanto, as mentiras virtuais encontram-se no poder da forma é necessária para pôr fim a uma espécie de cegueira em relação ao que é transitório, microscópico, a passagem das artes" (Buci-Glucksmann 2003).

19 Refiro-me aqui à noção de interconectividade e consciência global elaborada a partir de teorias taoístas que inspiraram minhas primeiras leituras (Capra, 1985) e que foram mais tarde complementadas por várias outras leituras sobre culturas orientais (Buci-Glucksmann 2001, 2003, Ho 1993, Gunji 1985).
} 
organização perceptiva (Pitozzi ${ }^{2009} b$ ).

\section{O corpo coletivo como uma estratégia de desestabilização}

De acordo com Crémézie (1997, citado em Boisclair 2008), diferentes estéticas corporais surgiram ao longo da história da dança: "[...] o "corpo rebelde" (Duncan), o "corpo bárbaro" (Nijinski), o "corpo místico" (St-Denis), o "corpo dinâmico" (Humphrey), o "corpo ctônico" (Wigman), o "corpo pulsional”(Graham), o "corpo articulado" (Cunningham), o "corpo tátil”(Paxton ), o "corpo fluido” (Brown) [...]”. Com a minha criação atual, eu trabalhei com a ideia de um corpo coletivo, no entanto, corpos "fluidos" e "táteis" também me interessaram como fonte de inspiração. Dois outros tipos de estética corporal foram também pertinentes: o "corpo introspectivo"(Butoh) e o "corpo coletivo" ${ }^{20}$ (Lygia Clark). Segundo a crítica cultural Louise Boisclair ${ }^{21}$ (2008), minha pesquisa parece desenvolver outra estética de dança: “uma 'trans(e)dança”, uma contração de transe (francês: transe), trans, recordando a transdisciplinaridade da minha pesquisa e trabalho de corpo, dança, e (e) para a energia, eletrônica, elasticidade e eletricidade.”

Boisclair descreve o "corpo coletivo" com o qual estou trabalhando como um "organismo larval". Esse corpo pertence a um gênero coletivo de ressonância (aqui eu faço referência às teorias de Rolnik), alimentada por estratégias somáticas como forma de renovar cinestesia e exteriocepção. De acordo com Boisclair (2008), um "corpo larval" pode ser entendido em termos de um "corpo embrionário":

Essa qualificação não se refere a corpos dançantes individuais que são enérgicos e maleáveis Ela define um corpo sonoro estendido num estado de recém'nascido' incoativo' inacabado' sempre buscando desenvolver'se e equilibrar'se. Este "corpo larval", criado a partir de um "corpo sonoro" estendido, representa um estado de gestação fluída em perpétuo movimento.

Para Boisclair (2008), "o espectador internaliza o trabalho, experienciando uma perda completa de suportes em um espaço mental e corporal estendido pela experiência [...].” Estas tecnologias facilitam, a aparição de uma criatura que é ao mesmo tempo física e digital, visual e aural, um "corpo coletivo", composto por corpos individuais que estão conectados como um "corpo sonoro" estendido, como se se tornassem um espelho de trocas invisíveis entre seres humanos na intimidade dos corpos físicos, energéticos e cinéticos, por um lado, e por outro, do digital e sonoro.

\section{Lentidão como uma apropriação de mudança cinestésica}

Outra estratégia de desestabilização ligada a estratégias de apropriação de mudanças cinestésicas consiste em explorar um novo tipo de temporalidade, particularmente no que diz respeito ao movimento. Uma certa lentidão, ao ponto de imobilidade, se necessário, pode produzir a impressão de que o tempo parou ou está suspenso. Esta estratégia permite que o coreógrafo inscreva uma reorganização do corpo dentro de um fluxo de movimentos mais precisos e compostos derivados de contacto e separação, mas também, no qual os corpos individuais perdem sua prioridade dentro do desenvolvimento de uma performance.

Eu desejava encenar um tipo diferente de temporalidade, coletiva, que não está vinculada a um corpo único e, portanto, para a articulação do movimento singular, mas sim para a construção e a relação de movimentos e temporalidades que possam trabalhar em uníssono ou ser diversificado através de encontros ou separações. Esta forma de temporalidade, como um modo de auto-organização que emprego, pode ser relacionada com a estratégia de movimento transitório de Trisha Brown e a uma radicalização dos "corpos táteis" de Paxton. No entanto, no meu trabalho, eu empurro as técnicas de Paxton de contato para um ponto de obsessão hipnótica, reunindo diversas temporalidades dentro do mesmo movimento.

Eu traço uma trajetória dentro da matéria. Este processo também é adquirido em relação à e por causa de uma certa experiência com tecnologia. Pode até ser descrito como um permitir uma renovação de trajetórias

\footnotetext{
20 As origens e os princípios em que assenta o corpo coletivo originam-se de um conceito desenvolvido por Lygia Clark relacionado a um 'canibalismo' cultural que, para Clark, é como "entrar uns nos corpos dos outros (...) uma dissoluçấo experimental de fronteiras psico-corporais entre as pessoas"(Brett 2004). Brett (2004) também observa que Clark, em seu trabalho artístico, "foi capaz de diluir a noção de superfície, resolver a dicotomia sujeito/objeto e propor a experiência de comunicação em modelos de diálogo, seu trabalho fornece um ponto de clareza em meio a esta confusão e torna-se ainda mais pertinente."

21 Louise Boisclair é crítica cultural e membro do grupo de pesquisa internacional que eu criei para meus estudos de doutorado. Ela esteve presente durante a maior parte das fases de transição e apresentações do meu trabalho.
} 
dentro da matéria do corpo, som e espaço. O nível a que estou me referindo envolve a compreensão e escuta de todas as possíveis passagens e transformações sensoriais que a tecnologia permite desenvolver experimentalmente e isso, em diferentes fases de intervenção. Mais uma vez, pode ser resumido como trabalho de organização sensorial e, portanto, de cinestesia. Depois, este modo de "escutar" e de aprender com os movimentos que ocorrem nas profundezas do corpo deve ser exteriorizado e transmitido para um público.

\section{Proximidade como uma estratégia de desconstrução e desestabilização}

Observou-se anteriormente que uma segunda perda de suporte resulta da proximidade. Como uma estratégia para desconstruir a hierarquia inata do corpo e para desestabilizar a percepção, o corpo coletivo, ou massa de corpos, dos quais tenho falado, constitui uma forma de repensar a forma do corpo. A proximidade dos espectadores aos artistas ajuda a "de-compor" a forma normal do corpo dentro do fluxo do movimento coletivo. Estou me dirigindo, assim, a diferentes modos de recepção com este material sensorial.

Durante uma recente fase da criação do trabalho, os espectadores foram posicionados extremamente perto dos corpos dos bailarinos, a menos de meio metro. Isto teve o efeito de intimidar as capacidades analíticas dos espectadores. Já não podiam analisar e compreender o corpo de uma maneira normal, por exemplo, como quando o corpo é visto isoladamente ou em pé. Eu também busquei inspiração na des-hierarquização de Bellmer na representação do corpo. De acordo com os comentários dos espectadores, parece que eles foram desafiados por esta complexa entidade. Uma sensação de imersão e empatia para com o corpo coletivo dos artistas, possibilitado pelo reconhecimento psico-físico, era o que eu havia desejado e isso realmente aconteceu para a maioria deles. Gostaria também de mencionar que eu estava inspirada por apenas um aspecto da des-hierarquização de Bellmer e não por outros aspectos, tais como a sua abordagem ao erotismo ou à perversão.

\section{Uma abordagem integrativa}

Para enfrentar os problemas associados com o pensamento ocidental reducionista, materialista e dualista, foi necessário desenvolver um tipo de pensamento integrativo. De acordo com Ho (1993), Ascott ([1966-1967] 2003), Koesthler ([1968] 1972), Burnham ([1.968, 1.969] 1.973) e Nobrega (2009), o pensamento integrativo envolve uma modalidade diferente de pensamento. Todos esses autores concordam que é essencial re-adequar a completa participação de um "ser inteligente: intelecto e sentimento, corpo e mente, espírito e intuição" (Ho 1993: 13). Embora eles desenvolvam suas análises em campos diferentes da dança, seus argumentos são do nosso interesse, porque podem ser ligados a um contexto cada vez mais interdisciplinar de pesquisa e de performance.

Como uma abordagem principal da minha investigação com bailarinos, pesquisadores e criadores, proponho uma estratégia de livre associação para estimular o pensamento integrativo, que tem pontos em comum com os de Ascott, concebidos no contexto de um programa inovador em arte-educação ([1966-67] 2003). Os principais elementos dessa estratégia que envolve trabalho prático enriquecido pela reflexão teórica, incluem primeiramente a criação de um ambiente que é polêmico, gerando perguntas em vez de propor respostas absolutas. Através da união de um grupo dinâmico de mentes criativas provenientes de diferentes campos (ciências, performance/dança, arquitetura, design, mídia, música, artes visuais), a idéia era, em segundo lugar, ser capaz de refletir, aprender e testar, elementos de um debate sobre os processos criativos dentro de um contexto interdisciplinar. Esta estratégia também envolve uma de-compartimentação da hierarquia disciplinar e a criação de um ambiente sincrético (com lugares e pessoas provenientes de diferentes culturas, visões e referências). Além disso, implica na consideração de diferentes tipos de literatura capazes de gerar novas ideias (Bataille ou Rolnik, por exemplo), e a análise, contato e intercâmbio com figuras importantes no campo das práticas performativas contemporâneas que integram tecnologia. Por último, a abordagem integrativa envolve uma interação orgânica dos diversos elementos que dizem respeito ao ato criativo e ao acesso prático a meios técnicos adequados durante um período de tempo prolongado com o financiamento necessário para assegurar essas operações. Esta dinâmica é capaz de produzir novas ideias. Ela também é capaz de estimular o desenvolvimento de novas capacidades de aprendizagem e de formação profissional. 


\section{Uma metodologia evolutiva como uma ferramenta para criação}

A pesquisa para este projeto foi realizada em um processo passo-a-passo, com cada fase do processo criativo (fase 1-2005, fase 2-2006, fase 3-2007 a 2008), tomando a forma de um laboratório no qual a expressão artística foi determinada por uma exploração de novas formas de vivenciar a corporalidade ${ }^{22}$. Quando falo de uma modificação da corporeidade neste contexto, refiro-me à corporalidade de todos aqueles que participaram nos laboratórios: os artistas, os criadores e os pesquisadores. Eu havia convidado os pesquisadores para participarem do processo artístico, colocando-os numa situação de risco da mesma forma que os criadores e os performers. Os pesquisadores haviam me contatado para estudar meu trabalho artístico, tanto no âmbito das suas próprias atividades acadêmicas quanto como críticos culturais. Eles passam a constituir um grupo de pesquisa que iniciei para examinar questões de novas práticas performativas contemporâneas que envolvem tecnologia. Eles vêm de grupos de pesquisa já existentes, como do laboratório Performativité et effets de présence da Université du Québec em Montréal, do laboratório Presence in contemporary artistic scene da Universidade de Exeter, Reino Unido, ou do Groupe SCÈNES : Systémique, complexité et nouvelles écritures scéniques da Laval University, Quebec. Para esses pesquisadores, participar de ensaios proporciona um espaço de ressonância física com suas próprias pesquisas e orienta as sessões de exploração teórica que organizo após cada apresentação do meu trabalho. Com essa metodologia, me empenho em instaurar uma complementaridade de inteligências proposta por Howard Gardner ([1983] (2006)) e Goleman ([1995] (1997)).

A tarefa desses pesquisadores consiste em gerar um retorno crítico e agirem como investigadores complementares. Somos da opinião de que o que era mais interessante no processo não era examinar os resultados de questionários que eu distribuía propondo questões ou metas que eu estabelecera, mas sim o que havia sido criado inconscientemente. Prática e teoria anteciparam e influenciaram-se mutuamente em uma ordem que era impossível de prever, e uma comunhão de diversas correntes "contaminaram" e influenciaram-se mutuamente de forma criativa. Aqui, o grupo assumiu um estatuto de pesquisadores de maneira semelhante aos artistas envolvidos. Nessa relação de pesquisa mútua, que é na verdade uma forma coletiva de pesquisa envolvendo ferramentas diferentes e complementares, sua participação tornou-se particularmente relevante. Esta metodologia pode, assim, ser considerada uma ferramenta para melhorar a experiência criativa através de um processo extremamente rico de exploração que foi primeiramente experimentado intuitivamente, mas agora está em uma fase de estruturação. Minha intenção é observar os meios pelos quais as estratégias criativas que desenvolvi podem ser incluídas e transmitidas numa lógica de pesquisa evolutiva que eu estou conduzindo atualmente. Um dos principais objetivos desta metodologia é a abordagem de material criativo como matéria viva que pode se transformar, evoluir e, espero, provocar fenômenos emergentes. Eu procuro pôr em marcha uma dinâmica de vida, na qual a noção de finalidade não tem sentido, mas o significado está relacionado à transformação, à evolução e ao experiemental. Por conseguinte, esta metodologia centra-se em ser/estar ao invés de fazer. Sua ambição é priorizar elementos ontológicos e essência em uma alquimia da realidade.

\section{Conclusão}

A metodologia descrita neste artigo se refere a uma nova abordagem performativa contemporânea e propõe que a inteligência cinestésica, entre outras coisas, quando reintroduzidos e reexaminada à luz dos processos cognitivos, põe em jogo a própria natureza da cognição. Ou seja, ela apoia aquilo que proponho como uma "re-integração" que pode ser transmitida através de processos de aprendizagem e ter um impacto como um princípio evolutivo e emergente nas artes cênicas. Essa dinâmica transversal e integradora cria um contexto em que modalidades sensoriais são estimuladas e levam à possibilidade de enriquecer e transformar a percepção. Autores como Pitozzi (2008a, 2009a, 2009b, 2010) e Quinz, trazem essas idéias de uma transformação de percepção à tona no contexto do corpo físico e performativo.

Como resultado da minha pesquisa, eu proponho a ideia de que a exploração de novas relações entre educação somática e tecnologia abre um outro campo de conhecimento necessário para a compreensão das mudanças que eu evoquei nesse artigo em que o corpo físico está irremediavelmente envolvido. Na sequência das

\footnotetext{
22 O presente texto trata principalmente da fase 3 do projeto que aconteceu durante nossa residência no Centre de développement choréographique Le Pacifique em Grenoble, na França, na primavera de 2008. Nós trabalhamos com o compositor Dominique Besson apenas para a exploração da fase 3.
} 
discussões que aconteceram na conferência Somatics and Technology em junho de 2012 na Universidade de Chichester, percebo o quanto o trabalho de artistas pós-modernos americanos definiram as bases para esta pesquisa. O presente está, assim, num estado de transformação. Espaço performativo é, sem dúvida, uma resposta para o futuro ...

\section{Referências}

(de) Andrade, O. (1928), 'Manifesto Antropófago'. Online in the English version n.d., "Cannibal Manifesto ”, http://feastofhateandfear.com/archives/andrade.html. Accessado em 30 Junho 2011.

Ascott, R. [1966-67] (2003), 'Behaviourist Art and the Cybernetic Vision', em Telematic Embrace: Visionary Theories of Art, Technology, and Consciousness, Berkeley, Los Angeles, London: University of California Press, pp.109-156.

Bernard, M. (2001), De la création chorégraphique, Pantin, France: Édition Centre national de la danse, Collection Recherches.

Boisclair, L. (2008), 'Isabelle Choinière de Corps Indice : Autour des Demoiselles d'Avignon' in Inter, art actuel 'Espaces sonores', Quebec : Les Éditions Intervention, no. 98, winter 2008, p. 52-56.

Brett, G. (2004) Carnaval of perception; Selected Writings on Art Guy Brett, London: Institute of International Visual Art inIVA.

Buci-Glucksmann, C. (2001), L’esthétique du temps au Japon, Du Zen au Virtuel, Paris: Galilée.

Buci-Glucksmann, C. (2003), 'Interview par Emanuele Quinz', in Quinz, E (ed.), Interfaces, Clermont-Ferrand: Anomalie, Digital_arts no. 3, pp.88-97.

Burnham, J. [1968; 1969] (1973), 'Preface' in Beyond Modern Sculpture: The effects of science and technology on the sculpture of this century, New York: George Braziller, pp. vii-x.

Burnham, J. [1968; 1969] (1973), 'Introduction: Form and Indecision, Reification, Object and System', in Beyond Modern Sculpture: The effects of science and technology on the sculpture of this century, New York: George Braziller, pp. 1-18.

(L.) Burns, S. (2009), 'La parole de l'artiste chercheur', in Gosselin, Pierre \& Le Coguiec, Éric (eds), La recherche création : pour une compréhension de la recherche en pratique artistique, Quebec: Presses de l'Université du Québec, pp.57-64.

Capra, F (1985) Le tao de la physique, Paris, France: Édition Sand.

Choinière, I. (2014), 'The interval as a new approach to interfaces: Towards a cognitive and aesthetic paradigm of communication in the performing arts' in de Kerckhove, Derrick \& Miranda de Almeida, Cristina (eds), The Point of Being (Chapter 4), New Castel upon Tyne, U.K.: Cambridge Scholars Publishing, pp.103-146.

Corin, F. (2001), 'Le sens du mouvement. Interview d'Alain Berthoz', in Nouvelles de Danse, no. 48/49, autumn-winter, Brussels, Belgium, p.8o.

Darriulat, J. (2006), 'Esthétique', in Blay, Michel (ed.) Dictionnaire des concepts philosophiques, France: Larousse CNRS Editions, pp.278-280.

Deleuze, G. \& Guattari, F. (1980), Milles Plateaux ; Capitalisme et schizophrénie 2, Paris, France: Les Éditions 
de Minuit, Collection Critique.

Dourthe, P. (1999) Bellmer; Le principe de perversion, France: Jean-Pierre Faur éditeur.

Fontaine, G. (2004), Les danses du temps : Recherches sur la notion de temps en danse contemporaine, Pantin, France: Édition Centre national de la danse, collection Recherches.

Fortin, S. (2009), 'Apport possible de l'ethnographie et de l'autoethnographie pour la recherche en pratique artistique', in Gosselin, Pierre \& Le Coguiec, Éric (eds), La recherche création : pour une compréhension de la recherche en pratique artistique, Quebec: Presses de l'Université du Québec, pp.97-110.

Gardner, H. [1983] (2006), Frame of Minds: The Theory of Multiple Intelligences, United States: Ed. Gardner.

Goleman, D. [1995] (1997), L’intelligence émotionnelle 1, Paris: Éditions Robert Laffont.

Gosselin, P. \& Le Coguiec, É. (2009), Introduction to Gosselin, Pierre \& Le Coguiec, Éric (eds), La recherche création : pour une compréhension de la recherche en pratique artistique, Quebec: Presses de l'Université du Québec, pp.1-6.

Gosselin, P. (2009), 'La recherche en pratique artistique : spécificité et paramètres pour le développement de méthodologies', in Gosselin, Pierre \& Le Coguiec, Éric (eds), La recherche création : pour une compréhension de la recherche en pratique artistique, Quebec : Presses de l'Université du Québec, pp.21-32.

Gromala, D. (2007) 'Towards a Phenomenological Theory of the Visceral in the Interactive Arts', Ph.D. thesis, Plymouth, United Kingdom: University of Plymouth, 15 July 2007 version.

Gunji, M. (1985) 'L'esthétique de la danse japonaise', in Alternatives théâtrales, no. 22-23, April-May 1985, Paris, p.12.

Ho, Mae-Wan (1993), The Rainbow and the Worm: The Physics of Organisms, Singapore; River Edge, New York, London, United Kingdom: World Scientific Publishing Co.

Koestler, A. [1969] (1971), 'Beyond Atomism and Holism - The concept of the holon', in Koestler, Arthur \& Smythies, J.R. (eds.), Beyond reductionism, new perspectives in the life of sciences: Proceedings of the Alpbach Symposium 1968, Boston: Beacon Press, pp. 192-232.

Kuypers, P. (2006), 'Des trous noirs : Un entretien avec Hubert Godard', in Nouvelles de Danse, no. 53, Scientifiquement Danse : Quand la danse puise aux sciences et réciproquement, Brussels, Belgium.

Laflamme, Y. (2009), 'La science de l'art/l'art de la science : une synergie propre à un nouvel esprit scientifique en recherche création', in Gosselin, Pierre \& Le Coguiec, Éric (eds), La recherche création ; pour une compréhension de la recherche en pratique artistique, Quebec : Presses de l'Université du Québec, pp.65-76.

Le Coguiec, É. (2009), 'Récit Méthodologique pour mener une autopoiétique', in Gosselin, Pierre \& Le Coguiec, Éric (eds), La recherche création ; pour une compréhension de la recherche en pratique artistique, Quebec : Presses de l'Université du Québec, pp.111-118.

Le Coguiec, É. (2009), 'Récit Méthodologique pour mener une autopoiétique', in Gosselin, Pierre \& Le Coguiec, Éric (eds), La recherche création ; pour une compréhension de la recherche en pratique artistique, Quebec : Presses de l’Université du Québec, pp.111-118.

Luz, C. (1975), 'Lygia Clark na Sorbonne : corpo-a-corpo no desbloqueio para a vivência ', in Vida das Artes 1, no. 3 August 1975, Rio de Janeiro, Brazil, p. 64.

(da) Nobrega, Carlos Augusto Moreira (2009), 'Art and Technology; coherence, connectedness and the integrative field', Ph.D. thesis, Plymouth, United Kingdom: University of Plymouth. 
Pavis, P. (2005), L'analyse des spectacles: théâtre, mime, danse-théâtre, cinéma, Paris : Éditions Armand Colin.

Pitozzi, E. (2008a), 'Sismographies de la présence', in the Journées d'études Effets de presence, effets du reel. 6 June, 2008. Montreal, Canada.

Pitozzi, E. (2008b), 'L'intima percezione del movimento : verso une fenomenologia della lentezza', in Art'O, $\mathrm{n}^{\circ} 25$, spring 2008. Bologna, Italy, p.42.

Pitozzi, E. (2009a), 'Spazio stereoscopico per corpo sonoro. Conversazione con Isabelle Choinière', in Art'O, no. 28, summer 2009, Bologna, Italy, pp. 58-65.

Pitozzi, E. (2009b), 'Espace stéréoscopique pour corps sonore. Conversation avec Isabelle Choinière', in Archée-périodique électronique, December 2009/Projets, section entretiens, Montreal, Canada, http://www. archee.qc.ca/.

Pitozzi, E. (2010), 'Étendre la peau; Scène, perception, dispositive technologiques', in Poissant, L. \& Tremblay, P. (eds.), Ensemble ailleurs; Together elsewhere, Quebec: Presses de l'Université du Québec, Collection Esthétique des arts médiatiques, pp. 321-340.

Poissant, L. (2009), 'Préface', in Gosselin, Pierre \& Le Coguiec, Éric (eds), La recherche création ; pour une compréhension de la recherche en pratique artistique, Quebec : Presses de l'Université du Québec, pp.VII-X.

Quinz, E. (2003a), 'Éditorial', in Quinz, E (ed.), Interfaces, (pp. 8-9), Clermont-Ferrand: Anomalie, Digital_ arts no. 3 .

Quinz, E. (2003b), 'Seuil de mutation. Notes sur la notion d'interface', in Quinz, E (ed.), Interfaces, Clermont-Ferrand: Anomalie, Digital_arts no. 3, pp. 10-15.

Rolnik, S. \& Diserens, C. (org.) (2005), 'Lygia Clark, De l'oeuvre à l'événement. Nous sommes le moule. A vous de donner le souffle', in Catalogue Editor Musée des Beaux-arts, Nantes, pp. 247-249.

Rolnik, S. (2006), Conference presented at the Forum F.A.Q. - Perguntas Sobre Arte, Consciência e tecnologia, SESC. / Premio Sergio Motta de Arte e tecnologia, 30 November-2 December 2006, Sao Paulo, Brazil.

Rolnik, S. (n.d.), 'Anthropophagic Subjectivity', http://caosmose.net/suelyrolnik/textos.htm. Accessado em 22 Maio 2007a.

Rolnik, S. (n.d.), 'Figures nouvelles du Chaos ; les mutations de la subjectivité contemporaine', http://caosmose.net/suelyrolnik/textos.htm. Accessado em 22 Maio 2007b.

Rolnik, S. (n.d.), 'L'hybride de Lygia Clark', http://caosmose.net/suelyrolnik/textos.htm. Accessado em 22 Maio 2007c.

Sasso, R. \& Villani, A. (2003) 'Le vocabulaire de Gilles Deleuze’, in Les Cahiers de Noesis, $\mathrm{n}^{\circ} 3$, spring, p.p.354355, http://www.pixander.com/vocabulaire-gilles-deleuze-vocabulary, http://www.caute.lautre.net/. Accessado em 8 Janeiro 2013.

Links de certos artistas citados

Stelarc

http://stelarc.org/?catID=20247. Accessado em 26 Junho 2011. 
http://www.k-danse.net/. Accessado em 19 Setembro 2008.

Palindrome (Robert Wechler)

http://www.palindrome.de/. Accessado em 19 Setembro 2008.

Troika Ranch

http://www.troikaranch.org/technology.html. Accessado em 19 Setembro 2008.

Kondition Pluriel

http://www.konditionpluriel.org/. Accessado em 19 Setembro 2010.

Recebido em 11/11/2014

Aprovado em 11/01/2015 